\title{
TLC profiling and antioxidant activity of phenolic compound from Sterculia oblongata bark extract
}

\author{
TRI MURNINGSIH", PRAPTIWI, LIANA, AHMAD FATHONI \\ Botany Division, Research Center for Biology, Indonesia Institute of Science. Jl. Raya Jakarta-Bogor Km 46, Cibinong, Bogor 16911, West Java, \\ Indonesia. Tel./fax: +62-21-8765063, `email: murningsiht@gmail.com
}

Manuscript received: 11 January 2018. Revision accepted: 20 February 2019.

\begin{abstract}
Murningsih T, Praptiwi, Liana, Fathoni A. 2019. TLC profiling and antioxidant activity of phenolic compound from Sterculia oblongata bark extract. Nusantara Bioscience 11: 44-48. In the present study, we investigated the total phenolic content and in- vitro antioxidant activity of Sterculia oblongata. Total phenolic content (TPC) of the methanol extract was examined by Folin-Ciocalteu reagent and gallic acid as standard. The in-vitro antioxidant activity was performed by DPPH free radical scavenging activity and $\beta$ carotene bleaching assay. The result showed that the TPC of methanol extract was the highest $(\mathrm{P}<0.05)$ compared to other extracts. There is a positive and significantly very high Pearson's correlation between antioxidant activity index (AAI) and TPC $(r=0.996)$. A negative and significantly high Pearson's correlation was obtained between IC50 value and TPC $(r=-0.885)$. The result of $\beta$-carotene bleaching assay showed that the rate of the decreased antioxidant activity of S.oblongata extract was lower than that of $\beta$ carotene/linoleic acid. The results suggest that the extract of $S$. oblongata can be used as a natural antioxidant. However, further investigation to isolate and identify the chemical compounds responsible for antioxidant was needed
\end{abstract}

Keywords: Antioxidant activity, Sterculia oblongata, TPC

\section{INTRODUCTION}

Oxygen is an important element for every living organism. Reactive oxygen species (ROS) is essential to energy supply, detoxification, chemical signaling, and immune function. It is continuously produced in the human body and controlled by endogenous enzymes (superoxide dismutase, glutathione peroxidase, catalase). The excessive production of ROS can lead to oxidative stress triggering damage in cell structures, including lipids, proteins, and DNA, and may cause many disorders such as cardiovascular, cancer, diabetes and other chronic diseases (Dimitrios 2006; Dzialo et al. 2016).

In order to counter the negative impact of excessive ROS in the body, the endogenous antioxidants are needed because the body does not large amounts of antioxidant reserves (Sunarni 2001). Antioxidant compounds prevent oxidative damages (Stanner et al.2004) and protect the organism from damage due to oxidative stress caused by free radicals (Silweke and Duodo 2007).

Plant-derived antioxidants, especially polyphenolic compounds, have gained considerable importance due to their potential health benefits (Iloki-Assanga et al. 2015). The antioxidant activity of phenolic compounds is mainly due to their redox properties, which allow them to act as reducing agents, hydrogen donors, singlet oxygen quenchers and metal chelators (Silweke and Duodo 2007; Behere et al. 2006; Huang et al. 2003). Phenolic compounds widely distributed in plants, they are found to be one group of the important secondary metabolites. Phenolic compounds are known for their biological properties. One of the most common functions of phenolic compounds is as antioxidant compounds, which is formed in the molecular structure. The molecular structure of phenolic compounds consisted of at least one phenol ring, in which the hydrogen is usually replaced by hydroxyl or another more active residue, methyl or acetyl. Antioxidant activity of the phenolics is resulted from the pattern and the degree of the substitutes (Cheynier 2012; Dzialo et al. 2016).

Several plant species from Sterculiaceae have been used as traditional medicines and their bioactive compounds have also been reported. Pterospermum acerifolium, in an example, used in traditional medicine for anticancer treatment (Balachandran and Govindarajan 2004), antioxidant and anti-inflammatory (Sannigrahi et al. 2010; Malik et al. 2012) and good DPPH radical scavenging activity with $\mathrm{IC}_{50}$ value $163.50 \mathrm{ug} / \mathrm{ml}$ (Kumar and Arora 2015). Several species of the genus Sterculia have been reported to have biological activities as antioxidant, antiinflammatory, antimicrobial and cytotoxic (El-Sherei et al. 2016).

To the best of our knowledge, the potential of $S$. oblongata as one species of Sterculiaceae has not yet been studied. This study aims to determine the total phenolic compounds of $S$. oblongata bark extract and its fractions of S. oblongata bark extract as well as the antioxidant activity.

\section{MATERIALS AND METHODS}

\section{Plant materials}

Sterculia oblongata bark used in this study was collected from Gunung Tilu, West Java, Indonesia. The plant sample was identified and authenticated in Herbarium 
Bogoriense -Botany Division, Research Center for Biology, Indonesian Institute of Sciences, Bogor, West Java, Indonesia.

\section{Preparation of plant extract}

The bark was cut into small pieces and air dried for several days. The dried bark was then ground into coarse powder. The powder $(300 \mathrm{~g})$ was macerated with methanol (1L) at room temperature for 48 hours. The filtrate was filtered with a Whatman filter paper. The process was repeated three times. All filtrates were pooled and concentrated using a rotary evaporator (Eyela, Japan) at low temperature $\left(45^{\circ} \mathrm{C}\right)$ under reduced pressure. The methanol extract was partitioned using solvents of increasing polarity (n-hexane, chloroform, and ethyl acetate). The partition in each solvent was repeated three times. All the three fractions were evaporated to dryness using a rotary evaporator (Muhit et al. 2010). Each fraction was stored in a refrigerator for further analysis.

\section{Qualitative and quantitative analysis of total phenolic contents}

Analysis of antioxidant activity and phenolic content of fractions qualitatively were done by TLC method (Fu et al. 2011). An aliquot of chloroform and ethyl acetate $(15 \mu \mathrm{L})$ fractions were loaded onto the different silica gel plate $\left(\mathrm{GF}_{254}\right)$ and allowed to dry for a few minutes. Afterwards, the plates were developed with $n$-hexane-chloroform $3: 7$ $\mathrm{v} / \mathrm{v})$ and toluene-ethylacetate-formic acid-methanol (15:15:4:1 v/v/v/v), respectively. The TLC work was done in 2 sets. One set of plates was visualized under ultraviolet light (254 and $366 \mathrm{~nm}$ ), and 1 set was visualized under visible light after sprayed with Folin-Ciocalteu's reagent (for phenolic compounds).

Quantitatively total phenolic compounds were measured by the Folin-Ciocalteu's method (Ismail et al. 2012). The total phenolic content was expressed as milligrams gallic acid equivalents per gram of dry plant extract (mg GAE/g DE) through the calibration curve of gallic acid with concentrations ranging from 6.25 to 200 $\mu \mathrm{g} / \mathrm{mL}$

One more set of plates were visualized under visible light after sprayed with DPPH solution in methanol (for antioxidant compounds) observed at $10 \mathrm{~min}$ after spraying.

\section{Antioxidant activity \\ Qualitative and quantitative analysis of DPPH free radical scavenging activity of methanolic extract}

DPPH performed qualitative determination of antioxidant activity on TLC. The same procedure was performed as in the qualitative analysis of phenolic contents. An aliquot of ten microliters of chloroform, ethyl acetate, methanol fractions $(10 \mathrm{mg} / \mathrm{ml})$ and gallic acid (standard of phenolic compound, $1 \mathrm{mg} / \mathrm{ml}$ ) was loaded onto the different silica gel plate $\left(\mathrm{GF}_{254}\right)$ and allowed to dry for a few minutes. Afterward, the plates were developed with $\mathrm{CHCl}_{2}: \mathrm{MeOH}: \mathrm{H}_{2} \mathrm{O}$ (6:4:1). The plate was air-dried to remove excess solvents then observed under $254 \mathrm{~nm}$, and $366 \mathrm{~nm}$. Phenolic compound was detected by spraying with Follin Ciocalteau reagent. Antioxidant activity was investigated by spraying with DPPH $0.2 \%$ in methanol and observed at 10 minutes after it was sprayed by DPPH solution.

Quantitative determination of antioxidant activity was conducted by DPPH free radical scavenging using Scherer and Godoy method (2009) with some modifications. It was applied in our study to determine the antioxidant activity index (AAI). Methanol extract $(750 \mu \mathrm{L})$ at different concentrations $(0.5-32 \mu \mathrm{g} / \mathrm{mL})$ were added to $61.5 \mu \mathrm{g} / \mathrm{mL}$ DPPH methanolic solution $(750 \mu \mathrm{L})$. In this study, methanol p.a and catechin were used as negative and positive controls, respectively. The samples were incubated for 90 minutes in the dark condition at room temperature. The absorbances of the samples were measured at $517 \mathrm{~nm}$ using UV-VIS spectrophotometry (UV mini 1240 model, Shimadzu). The $\mathrm{IC}_{50}$ value to indicate antioxidant capacity was calculated by linear regression equation between the percentage of inhibition and the concentration of the sample. Antioxidant activity index (AAI) was calculated as follows:

$$
\mathrm{AAI}=\frac{\text { Final concentration of DPPH in the reaction }}{\mathrm{IC}_{50}}
$$

\section{$\beta$-Carotene bleaching (BCB) assay}

The antioxidant activity was evaluated according to the $\beta$-carotene linoleic model system based on the procedure of Mishra (Mishra et al. 2009). $2 \mathrm{~mL}$ of a solution of $\beta$ carotene in chloroform $(5 \mathrm{mg} / \mathrm{mL})$ was pipetted into a flask containing $200 \mu \mathrm{L}$ of linoleic acid and $400 \mu \mathrm{L}$ of Tween 40. The chloroform was removed under vacuum at $45^{\circ} \mathrm{C}$, and then $100 \mathrm{~mL}$ of distilled water was slowly added to the semi-solid residue to form an emulsion. $5 \mathrm{~mL}$ of the emulsion was added into a tube containing $0.2 \mathrm{~mL}$ of extract or standard solution at $100 \mathrm{mg} / \mathrm{mL}$ concentration and the absorbance was measured at $470 \mathrm{~nm}$ using a UVVis spectrophotometer (UV mini 1240 model, Shimadzu). The tubes were incubated in a water bath at $50^{\circ} \mathrm{C}$ and the measurement was conducted at 15 min interval up to 120 min. Vitamin E and BHT (Butylhydroxytoluene) were used as positive control. The experiment was carried out in triplicate. Degradation rate (DR) of the sample was calculated according to the first order kinetics as described by Olugbami et al. (2015):

$$
\mathrm{DR}_{\text {sample }} \text { or } \mathrm{DR}_{\text {standard }}=\frac{\left(\ln \left(\frac{\mathrm{A}_{0}}{\mathrm{~A}_{\mathrm{t}}}\right)\right)}{t}
$$

Where: $\ln =$ natural $\log ; \mathrm{A}_{0}=$ initial absorbance at time $0 \mathrm{~min} ; \mathrm{A}_{\mathrm{t}}=$ absorbance at $15,30,45,60,75,90,105$ and 120 min of incubation; $t=15,30,45,60,75,90,105$ and $120 \mathrm{~min}$. Antioxidant activity (AA) was expressed as percent of inhibition relative to the control by using the equation as follows:

$$
\mathrm{AA}=\left(\frac{\mathrm{DR}_{\text {control }}-\mathrm{DR}_{\text {sample or standard }}}{\mathrm{DR}_{\text {control }}}\right) \times 100 \%
$$




\section{Statistical analysis}

Statistical analysis of variance of total phenolic contents (TPC), IC50 and antioxidant activity index (AAI) values were performed by Duncan's multiple-range tests using SPSS 16.0. Experiment was performed in triplicate and expressed as mean \pm SD. Values in each column with different letter are significantly different $(\mathrm{P}<0.05)$.

\section{Correlation test between antioxidant activity and total phenolic contents}

Correlation test between antioxidant activity by DPPH assay and total phenolic content (TPC) was carried out by Pearson's correlation $(\mathrm{P}<0.01)$.

\section{RESULTS AND DISCUSSION}

\section{Qualitative and quantitative analysis of total phenolic compounds}

The result showed that total phenolic content of fractions of $S$. oblongata (chloroform, ethyl acetate, and methanol) were $118.68 \pm 0.120,311.53 \pm 0.120$, and $564.38 \pm 0.417 \mathrm{mg}$ gallic acid equivalent $(\mathrm{GAE}) / \mathrm{g}$ dry extract plant, respectively. Phenolic compounds act as antioxidant because of their redox properties (Soobrattee et al. 2005). According to Baba and Malik (2015), the phenolic content of the extract could be used as antioxidant activity screening because of their free radical scavenging ability, by adsorption and neutralization of the free radicals (Osawa 1994). The result of phenolic compounds detection in chloroform, ethyl acetate, methanol fractions and gallic acid (standard) resulted in the blue color bands after sprayed with Follin Ciocalteau reagent were performed in Fig.1.C, while the secondary metabolites were observed under UV wavelength of 254 and $366 \mathrm{~nm}$ (Fig.1.A and B), respectively. These TLC chromatographic patterns and the spot position between the antioxidant activity and phenolic compounds from all fractions (chloroform, ethyl acetate and methanol) indicated the same pattern in Fig.1.C and D.

\section{Antioxidant activity}

Qualitative and quantitative analysis of DPPH free radical scavenging activity

TLC-bioautography of fractions showed that methanol fraction had several active chemical compounds as free radical scavengers indicated by white bands formation (Figure 1.D). This result of this study showed that methanol extract of $S$. oblongata had powerful antioxidant activity based on the $\mathrm{IC}_{50}$ value $(1.6855 \pm 0.0005 \mu \mathrm{g} / \mathrm{mL})$ and antioxidant activity index (AAI) value $=18.2440 \pm$ 0.0055 (Table 1). This could be due to the high phenolic content of the methanol extract. The total phenolic content of methanol extract was the highest of all used extract solution (Table 1.). After the fractionation process, some of phenolic compounds were dissolved in the chloroform fraction and partly in the ethyl acetate. The values of $\mathrm{IC}_{50}$ and AAI of the fractions were presented in Table 1. Phenolic compounds found in vegetables, fruits or medicinal plants are known for their antioxidant potential and their role in the prevention of human diseases (Cai et al. 2004).

Based on $\mathrm{IC}_{50}$ and $\mathrm{AAI}$ values, it can be concluded that the methanol extract has better activity as DPPH free radical scavenger than other fractions (ethyl acetate and dichloromethane fractions). The smaller the $\mathrm{IC}_{50}$ value, the smaller concentration of extract were needed to inhibit 50\% of free radicals. This might be caused by phenolic compounds are more extractable in the ethyl acetate compared to other fractions because phenolic compounds have the same polarity with ethyl acetate (semi-polar). There is also the possibility that phenolic compounds in ethyl acetate extract have different chemical structure compared to phenolic compounds in methanol and chloroform fractions.
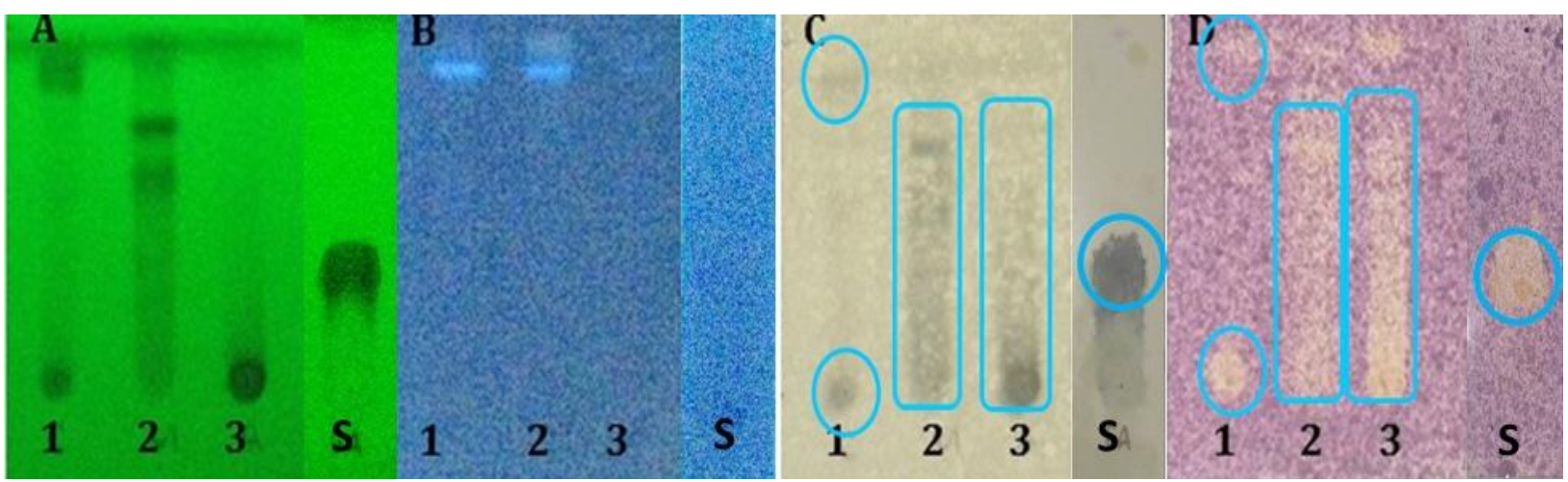

Figure 1. TLC bioautography of S.oblongata extracts as antioxidant activity by DPPH assay using $\mathrm{CHCl}_{2}: \mathrm{MeOH}^{\mathrm{H}} \mathrm{H}_{2} \mathrm{O}(6: 4: 1)$. A: observation at $254 \mathrm{~nm}$ wavelength, B: observation at $366 \mathrm{~nm}$ wavelength, C: phenolic contents observation after sprayed with Follin Ciocalteau reagent, D: antioxidant activity observation after sprayed with DPPH $0.2 \%$ in Methanol. 1: $\mathrm{CHCl}_{2}$ extract of $S$. oblongata, 2: EtOAc extract of $S$. oblongata, 3: MeOH extract of $S$. oblongata, S: Gallic acid (phenolic compound standard) 
Table 1. TPC, IC 50 and AAI values of $S$. oblongata extract/fractions

\begin{tabular}{|c|c|c|c|c|}
\hline Extract solution & $\begin{array}{c}\text { TPC } \\
\text { (mg GAE/g dry extract }\end{array}$ & $\begin{array}{c}\mathrm{IC}_{50} \\
(\mu \mathrm{g} / \mathrm{mL})\end{array}$ & AAI & Category of AAI \\
\hline Methanol & $564.38 \pm 0.417^{\mathrm{a}}$ & $1.6855 \pm 0.0005^{\mathrm{b}}$ & $18.2440 \pm 0.0055^{\mathrm{b}}$ & Very strong \\
\hline Ethyl acetate & $311.53 \pm 0.120^{\mathrm{b}}$ & $4.1950 \pm 0.0301^{\mathrm{c}}$ & $7.3301 \pm 0.0053^{c}$ & Very strong \\
\hline Chloroform & $118.68 \pm 0.120^{c}$ & $21.6174 \pm 0.0191^{\mathrm{d}}$ & $1.4225 \pm 0.0013^{\mathrm{d}}$ & Strong \\
\hline Catechin & NT & $0.7602 \pm 0.0006^{\mathrm{a}}$ & $40.4480 \pm 0.0021^{\mathrm{a}}$ & Very strong \\
\hline
\end{tabular}

Note: NT: Not Tested. Statistical analysis of variance was performed by Duncan's multiple-range tests using SPSS 16.0. Experiment was performed in triplicate and expressed as mean \pm SD. Values in each column with different letter are significantly different $(\mathrm{P}<0.05)$. Category of AAI value: weak $<0.05<$ moderate $<1<$ strong $<2<$ very strong (Scherer and Godoy 2009)

\section{Correlation test between antioxidant activity and total phenolic content}

Correlation test between antioxidant activity by DPPH assay and total phenolic content (TPC) was carried out by Pearson's correlation. The result showed that increasing TPC value contributes to the increase in AAI value. There was a positive and significantly very strong Pearson's correlation between TPC and AAI value $(r=0.996)$ $(\mathrm{P}<0.01)$. However, a negative and significantly high Pearson's correlation between TPC and $\mathrm{IC}_{50}(\mathrm{r}=-0.885)$ were also shown. This was due to the decrease in $\mathrm{IC}_{50}$ value would increase the antioxidant activity. This result was in accordance with Dudung (2011) study on S.oblongata leaves extracts showed that a positive correlation was shown between total phenol content and antioxidant activity ( $\mathrm{r}=0.9914)$.

\section{$\beta$-carotene bleaching assay: Antioxidant activity}

Based on the $\beta$-carotene bleaching assay, linoleic acid which was incubated at $50^{\circ} \mathrm{C}$ produced free radicals (hydroperoxides). In the absence of an antioxidant, betacarotene underwent rapid discoloration in this assay. Discoloration of a $\beta$-carotene solution (yellowish color) due to the breaking of $\pi$-conjugation in the presence of radical species that generated from the autoxidation of linoleic acid by heating under air atmosphere (Ueno et al 2014). Moreover, Ueno et al. (2014) stated that the addition of antioxidant into the solution would retard discoloration by competing for the reaction between $\beta$-carotene and antioxidant with the subjected radicals.

Figure 2. showed that the absorbance value of negative control decreased rapidly and color degradation (bleaching) could be observed clearly. This was due to the absence of antioxidant compounds in the negative control. The presence of antioxidants can delay the extent of $\beta$-carotene bleaching by neutralizing the linoleate free radicals. Thus, the degradation rate of $\beta$-carotene-linoleate could be used as an indication of the antioxidant activity. The $\beta$-carotene bleaching rate of vitamin E and BHT was relatively stable indicating the effectiveness of those positive control in preventing degradation of $\beta$-carotene. Degradation rate of $\beta$-carotene in negative control was the highest amongst positive controls and $S$. oblongata extract. (Maisarah et al. 2013). (Figure 2). This result might show that methanol extract of $S$. oblongata contained the antioxidant compounds but the activity was not as strong as vitamin $\mathrm{E}$ and BHT.

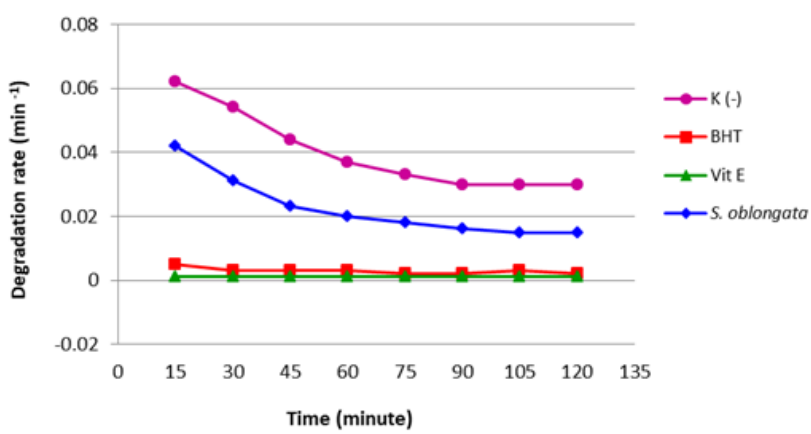

Figure 2. The degradation rate of $\beta$-carotene in the methanol extract of $S$. oblongata bark, the negative control and positive controls of BHT and vitamin E. $(n=3)$

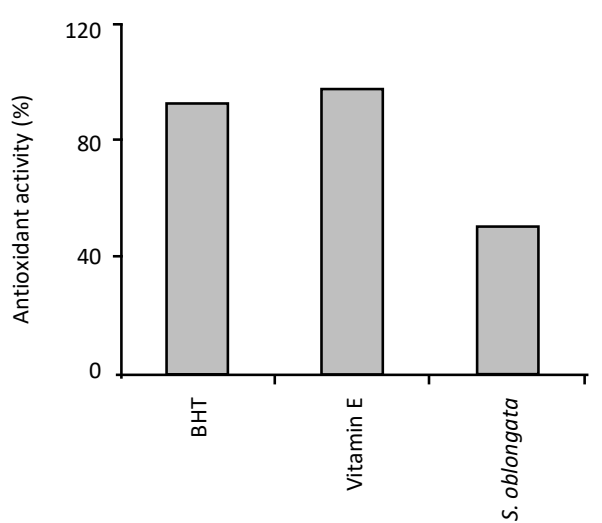

Figure 3. Antioxidant activity (\% inhibition of BCB) of $S$. oblongata and positive control BHT and vitamin E observed in 120 minutes.

The antioxidant activity of $S$. oblongata methanol extract, negative control and positive controls of BHT and vitamin $\mathrm{E}$ by $\beta$-carotene bleaching assay observed in 120 minutes was presented in Figure 3. Antioxidant activity of S. oblongata $(50 \pm 0,02 \%)$ was lower than BHT $(93,3 \pm$ $0,01 \%)$ and vitamin $\mathrm{E}(96,7 \pm 0,02 \%)$. This result indicated that the extract of $S$. oblongata contains chemical compounds with the ability to inhibit the oxidation of linoleic acid. The previous study by Murningsih (2015) shows that the extract has antioxidant activity by measuring the ability of S.oblongata extract to reduce molybdenum $\left(\mathrm{Mo}^{6+}\right.$ to $\left.\mathrm{Mo}^{5+}\right), \mathrm{Cu}^{2+}$ to $\mathrm{Cu}^{+}$and $\mathrm{Fe}^{3+}$ to $\mathrm{Fe}^{2+}$. 
In conclusion, this study showed that methanol and ethyl acetate extracts of $S$. oblongata have very strong DPPH free radical scavenging activity. While, the $\beta$ carotene bleaching assay confirmed that the extracts have antioxidant activity. The antioxidant activity has positive Pearson's correlation with total phenolic compounds. Further study to isolate the antioxidant compounds needs to be done.

\section{REFERENCES}

Baba SA, Malik SA. 2015. Determination of total phenolic and flavonoid content, antimicrobial and antioxidant activity of a root extract of Arisaema jacquemontii Blume. J Taibah Univ Sci 9: 449-454.

Balachandran P, Govindarajan R. 2011. Cancer: An ayurvedic perspective. Pharmacol Res 51: 19-30. DOI: 10.1016/j.phrs.2004.04.010

Behere B, Verma N, Sonone A, Makhija U. 2006. Determination of antioxidative potential of lichen Usnea ghattensis in vitro. LWT-Food Sci Technol 39: 80-85.

Cai Y, Luo Q, Sun M, Corke H. 2004. Antioxidant activity and phenolic compounds of 112 traditional Chinese medicinal plants associated with anticancer. Life Sci 74: 2157-2184.

Cheynier V. 2012. Phenolic compounds: from plants to foods. Phytochem Rev 11: 153-177. DOI: 10.1007/s11101-012-9242-8

Dimitrios B. 2006. Sources of natural Phenolic antioxidants. Trends Food Sci Technol 17: 505-512.

Działo M, Mierziak J, Korzun U, Preisner M, Szopa J, Kulma A. 2016. The Potential of Plant Phenolics in Prevention and Therapy of Skin Disorders. Intl J Mol Sci 17: 160. DOI: 10.3390/ijms17020160

El-Sherei MM, Ragheb AY, El Said Kassem M, Ali Mosharrafa S, Abdel Megied Saleh N. 2016. Phytochemistry, biological activities and economical uses of the genus Sterculia and the related genera: A review. Asian Pacific J Trop Dis 6 (6): 492-501

Fu L, Xu BT, Xu XR, Gan RY, Zhang Y, Xia EQ. 2011. Antioxidant capacities and total phenolic contents of 62 fruits. Food Chem 129: 345-350.

Huang S, Yen G, Chang L, Yen W, Duh P. 2003. Identification of an antioxidant ethyl protocatechuate, in peanut seed testa. J Agric Food Chem 51: 2380-2383.

Iloki-Assanga SB, Lewis-Luján LM, Lara-Espinoza CL, Gil-Salido AA, Fernandez-Angulo D, Rubio-Pino JL, Haines DD. 2015. Solvent effects on phytochemical constituent profiles and antioxidant activities, using four different extraction formulations for analysis of Bucida buceras L. and Phoradendron californicum. BMC Res Notes 8: 396. DOI: 10.1186/s13104-015-1388-1

Ismail J, Runtuwene MRJ, Fatimah F. 2012. Penentuan total fenolik dan uji aktivitas antioksidan pada biji dan kulit buah pinang yaki (Areca vestiaria Giseke). Jurnal Ilmiah Sains 12 (2): 84-88. [Indonesian]
Kumar A, Arora S. 2015. Role of phenolic and flavonoid compounds from selected plants in inhibiting pro-oxidants elicited strand breaks in plasmid pBR322 DNA. Intl J Pharmacogn Phytochem Res 7 (3): 401404.

Maisarah AM, Amira NB, Asmah R, Fauziah O. 2013. Antioxidant analysis of different parts of Carica papaya. Intl Food Res J 20 (3): 1043-1048.

Malik SK, Khan Z, Ajaib M. 2012. Investigation of in vitro antioxidant potential of ethnobotanically important tree, Pterospermum acerifolium. Pakistan J Bot 44: 105-109.

Mishra J, Yousuf A, Aradhana RDS. 2009. Phytochemical investigation and in-vitro antioxidant potential of leaves of Murraya koenigii. Intl J Integrat Biol 7 (3): 171-174.

Muhit AM, Tareq SM, Apu AS, Basak D, Islam MS. 2010. Isolation and identification of compounds from the leaf extract of Dillenia indica Linn. Bangladesh Pharmaceut J 13 (1): 49-53.

Murningsih T. 2015. Kapasitas antioksidan ekstrak beberapa jenis tumbuhan dari Gunung Tilu. Abstrak Seminar NasionalMasyarakat Biodiversitas Indonesia (MBI), Bandung,13 Juni 2015. [Indonesian]

Olugbami JO, Gbadegesin MA, Odunola OA.2015. In vitro free radical scavenging and antioxidant properties of ethanol extract of Terminalia glaucescens. Pharmacogn Res 7 (1): 49-56.

Osawa T. 1994. Novel natural antioxidants for utilization in food and biological systems. In: Uritani L, Garcia VV, Mendoza EM. (eds.). Post Harvest Biochemistry of Plant Food Materials in Tropics, Japan Scientific Societies Press, Tokyo, Japan.

Sannigrahi S, Parida S, Patro VJ, Mishra US, Pathak A. 2010. Antioxidant and anti-inflammatory potential of Pterospermum acerifolium. Intl $\mathbf{J}$ Pharmaceut Sci Rev Res 2 (1): 1-5.

Scherer R, Godoy H.T. 2009. Antioxidant activity index (AAI) by the 2,2diphenyl-1-picrylhydrazyl method. Food Chemistry 112 (3): 654-658. DOI: $10.1016 /$ j. foodchem.2008.06.026.

Sikwese F, Duodo K. 2007. Antioxidant effects of crude phenolic extracts from sorghum bran in sunflower oil in the presence of ferric ions. Food Chem 104: 324-331.

Soobrattee MA, Neergheen VS, Luximon-Ramma A, Aruoma OI, Bahorun OT. 2005. Phenolics as potential antioxidant therapeutic agents: mechanism and actions. Mutat Res Fundam Mol 579: 200213.

Stanner SA, Hughes J, Kelly CN, Buttris JA. 2004. Review of the epidemiological evidence for the'antioxidant hypothesis'. Public Health Nutr 7: 407-422.

Sunarni T. 2001. Aktivitas antioksidan penangkap radikal bebas beberapa kecambah dari bijih tanaman familia Papilionaceae. Jurnal Farmasi Indonesia 2 (2): 53-61. [Indonesian]

Takao LK, Imatomi M, Gualtieri SCJ. 2015. Antioxidant activity and phenolic content of leaf infusions of Myrtaceae species from Cerrado (Brazilian savanna). Braz J Biol 75 (4): 948-952. DOI: 10.1590/15196984.03314

Ueno H, Yamakura S, Arastoo RS, Oshima T, Kokubo K. 2014. Systematic evaluation and mechanistic investigation of antioxidant activity of fullerenols using $\beta$-carotene bleaching assay. J Nanomaterials. Article ID 802596. DOI: 10.1155/2014/802596. 